\title{
ANALISIS KEARIFAN LOKAL MASYARAKAT DALAM MENJAGA SUMBER DAYA AIR
}

\author{
(Study kasus Desa Pisak Kecamatan 17 kabupaten Bengkayang)
}

\author{
Guido DwiAdmojo ${ }^{1}$, Kartini ${ }^{1}$, Dian Rahayu Jati² \\ 1)Program Studi Teknik Lingkungan Jurusan Teknik Sipil Fakultas Teknik Universitas Tanjungpura, Pontianak \\ 2)Program Studi Teknik Sipil Jurusan Teknik Sipil Fakultas Teknik Universitas Tanjungpura, Pontianak \\ Email :Guidoadmojo@gmail.com
}

\begin{abstract}
ABSTRAK
Kearifan lokal ikut berperan dalam pengelolaan sumberdaya alam dan lingkungannya. Namun demikian kearifan lokal juga tidak lepas dari berbagai tantangan seperti: bertambahnya terus jumlah penduduk, teknologi modern dan budaya, modal besar serta kemiskinan dan kesenjangan. Layaknya masyarakat Desa Pisak memberlakukan larangan-larangan yang diterapkan oleh masyarakat Desa untuk menjaga kelestarian DAS (Daerah Aliran Sungai) Sungai agar tidak menciptakan kerusakan yang berdampak buruk bagi masyarakat setempat. Penelitian ini bertujuan menganalisis peran masyarakat dalam menjaga kelestarian sumber daya air, serta menganalisa implementasi masyarakat dalam menjaga kelestarian sumber daya air dilihat dari perbandingan peta selama 2 tahun. Penelitian menggunakan metode tringulasi yaitu kombinasi dari teknik pengumpulan data dengan menggunakan metode wawancara mendalam, pengamatan berperanserta terbatas dan penelusuan (analisis) data sekunder, serta menghitung jumlah penggunaan lahan selama 2 tahun. Dari hasil penelitian di dapat masyarakat Desa Pisak masih menerapkan aturan-aturan atau larangan seperti dilarang menebang pohon secara sembarangan, dilarang memasuki hutan secara sembarangan selain itu juga masyarakat masih memegang teguh adatistiadat yang berasal dari leluhur mereka dengan masih melaksanakan ritual adat. Untuk jumlah penggunaan lahan DAS sungai Tanggi memiliki luasan 14,069 ha. Luasan penggunaan lahan Desa Pisak pada tahun 2016 sebesar 405,301 ha, sedangkan untuk tahun 2105 sebesar 395,379 ha pengurangannya selama 2 tahun sebesar 9,922 ha. Pengurangan tersebut disebabkan kebakaran hutan yang terjadi pada tahun 2015, lahan yang terbakar diambil alih oleh pemerintan untuk dilakukan proses pemulihan lahan.
\end{abstract}

Kata kunci:Kearifan Lokal, Sumber Daya Air, Penggunaan Lahan

\begin{abstract}
Local wisdom plays a role in the management of natural resources and their surroundings. However, local wisdom is also not separated from various challenges such as: the continued increase of the population, modern technology and culture, massive capital, as well as poverty and social gap. Like the community of Pisak Village who impose and apply the restrictions to maintain the sustainability of river watershed and to prevent the possible damage that may harm the local community. This study aims to analyze the role of the community in maintaining the sustainability of water resources, as well as to analyze the community implementation in maintaining the sustainability of water resources as seen from the comparison of the map for 2 years. The research used a tringulation method which is a combination of data collection techniques by using in-depth interviews, observation of limited amount of participants and secondary data analysis, and calculation of the total land use area for 2 years. From the results of the research, it is concluded that Pisak Village community still apply the rules or restrictions such as prohibition of cutting down trees in an indiscriminate manner and ban of entering the forest arbitrarily. In addition to that, the villagers also still hold the customs derived from their ancestors firmly by still performing the customary rituals. Meanwhile, The total area of land use in Sungai Tanggi watershed is 14.069 ha. The area of land use in Pisak Village in 2016 amounted to 405,301 ha, while for the year of 2105 amounted to 395.379 ha. The reduction for 2 years amounted
\end{abstract}


to $9,922 \mathrm{ha}$. This reduction is due to the forest fires that occurred in 2015, the burnt land is taken over by the government for the process of land recovery.

Keywords: Local Wisdom, Water Resources, Land Use. 


\section{PENDAhUluAN}

Sumber daya air di kabupaten Bengkayang merupakan salah satu sumber daya alam penting bagi kehidupan manusia. Meningkatnya jumlah penduduk dan kegiatan pembangunan telah meningkatkan kebutuhan terhadap sumber daya air. Di lain pihak ketersediaan sumber daya air semakin terbatas, bahkan di beberapa tempat dikategorikan berada dalam kondisi kritis. Hal ini disebabkan oleh berbagai faktor seperti pencemaran, penggundulan hutan, kegiatan pertanian yang mengabaikan kelestarian lingkungan, dan perubahan fungsi daerah tangkapan air. Oleh karena itu kearifan lokal ikut berperan dalam pengelolaan sumberdaya alam dan lingkungannya. Namun demikian kearifan lokal juga tidak lepas dari berbagai tantangan seperti: bertambahnya terus jumlah penduduk, teknologi modern dan budaya, modal besar serta kemiskinan dan kesenjangan. Adapun prospek kearifan lokal di masa depan sangat dipengaruhi oleh pengetahuan masyarakat, inovasi teknologi, permintaan pasar, pemanfaatan dan pelestarian keanekaragaman hayati di lingkungannya serta berbagai kebijakan pemerintah yang berkaitan langsung dengan pengelolaan sumberdaya alam dan lingkungan serta peran masyarakat lokal. Layaknya masyarakat Desa Pisak memberlakukan larangan-larangan yang diterapkan oleh masyarakat Desa untuk menjaga kelestarian DAS Sungai agar tidak menciptakan kerusakan yang berdampak buruk bagi masyarakat setempat. Masyarakat Desa Pisak memanfaatkan air sungai sebagai sumber air untuk kebutuhan sehari-hari, Sungai yang berada di Desa Pisak Kecamatan Tujuh Belas adalah Sungai Tanggi, Sungai Tanggi merupakan DAS yang berhulu di Desa Pisak Dengan Rentang hilir Sampai DAS Sungai Sambas, Sungai Tanggi Sendiri dilalui oleh beberapa Riam yang dijadikan objek wisata daerah setempat dan Pemerintah Kabupaten Bengkayang. Tujuan penelitian ini adalah menganalisis peran masyarakat dalam menjaga kelestarian sumber daya air, serta menganalisa implementasi masyarakat dalam menjaga kelestarian sumber daya air dilihat dari perbandingan peta selama 2 tahun.

\section{METODE PENELITIAN}

a. Waktu Dan Tempat

Penelitian ini merupakan observasi lapangan yaitu pengumpulan data berupa dokumentasi gambar, yang dilakukan di Desa Pisak Kecamatan Tujuh Belas Kabupaten Bengkayang.

\section{b. Prosedur Penelitian}

Penelitian ini merupakan penelitian observasi adalah pengumpulan data berupa dokumentasi gambar, selain itu juga data diperoleh melalui observasi dilapangan dengan wawancara langsung dengan masyarakat desa agar mendapatkan fakta berdasarkan pemahaman subyek penelitian, mengetengahkan hasil pengamatan itu secara sangat rinci. Pendekatan kualitatif ini digunakan untuk mengidentifikasi dari keberadaan kearifan lokal di Desa Pisak dan menggambarkan kearifan lokal berdasarkan pemahaman subyek, dan data lainnya adalah data Kuantitatif yang diperoleh dari, BPS (Badan Pusat Statistik) dan Bapeda (Badan Pembangunan Daerah) Kabupaten Bengkayang yang berupa data Peta berformat SHP (Shape file) selama 2 tahun yaitu tahun 2015 dan tahun 2016 yang diolah menggunakan aplikasi ArcGis. Selain itu kombinasi dari teknik pengumpulan data dengan menggunakan metode Triangulasi yaitu : 


\section{A. Wawancara Mendalam}

Untuk memilih informan, peneliti ini akan menggunakan teknik bola salju (snowball sampling) yaitu peneliti harus mengenal beberapa masyarakat desa yang akan dijadikan informan kunci terlebih dahulu dan kemudian meminta mereka untuk memperkenalkan informan lain yang dapat di wawancarai. Informan kunci yang akan dipilih secara purposive yaitu kepala adat, kuncen, dan kepala dusun. Ketiga informan kunci ini dipilih karena mereka merupakan pemimpin informal dan pemimpin formal di desa Dawar.

B. Pengamatan Berperanserta Terbatas

Pengamatan berperanserta menunjuk pada proses penelitian yang mempersyaratkan interaksi sosial antara peneliti dengan masyarakat desa. Peneliti akan menggunakan pengamatan berperan serta-terbatas, yaitu dengan tidak merahasiakan identitas peneliti. Pengamatan akan dilakukan dengan cara wawancara informal untuk mengidentifikasi kearifan lokal dalam pengelolaan sumberdaya air berdasarkan persepsi masyarakat.

C. Penelusuran (analisis) Data Sekunder

Penelusuran dokumen dilakukan sebagai penguatan terhadap data-data yang tidak bisa dilengkapi dari pengamatan berperanserta dan wawancara mendalam. Data sekunder diperoleh dengan menganalisis dan melakukan kajian pustaka terhadap berbagai literatur, yakni jurnal, buku, makalah dan informasi dari internet yang terkait dengan topik penelitian. Selain itu juga penelitian ini melakukan perbandingan peta topografi selama beberapa tahun di daerah tersebut untuk melihat kondisi perubahan topogafi yang dijadikan acuan atau hasil dari kearifan local masyarakat dalam menjaga sumber daya air didesa Dawar.

\section{HASIL DAN PEMBAHASAN}

\section{a. Peran Serta masyarakat}

Pada Desa Pisak sarana dan prasarana yang telah ada diantarannya: sarana pendidikan, sarana peribadatan, sarana kesehatan, sarana trasportasi, sarana komunikasi. Untuk sarana trasportasi akses menuju ke Desa pisak masih dikatakan belum memenuhi Standar atau kurang baik, jalan penghubung ke desa masih mengalami kerusakan dan belum adanya perbaikan dari pemerintah pusat maupun pemerintah daerah.

Desa Pisak juga telah memiliki PDAM (Perusahaan Daerah Air Minum), PDAM tersebut telah ada selama kurun waktu 10 tahun yang diberikan oleh pihak misi Gereja Katolik. Untuk Pengerjaan dan pemeliharaan PDAM di desa Pisak dilakukan oleh warga dimana dikelola oleh lembaga swadaya masyarakat, karakteristik sumber air sungai Tanggi berdasarkan pengamatan masyarakat/responden yang menggunakan air sungai setiap hari sebagian besar menilai bahwa air sungai sudah baik atau sangat baik untuk dikonsumsi atau dimanfaatkan untuk berbagai jenis kegiatan yang membutuhkan air, karena air sungai Tanggi tidak berbau, tidak berasa, dan tidak berwarna, selain itu juga kepercayaan masyarakan akan sumber air sungai Tanggi yang masih terjaga kelestariannya. sungai Tanggi di jadikan sumber air baku PDAM untuk kecamatan Tujuh Belas dan Kecamatan Sanggau Ledo, karakteristik sumber air baku PDAM telah memenuhi standar baku mutu dapat dilihat pada Tabel 1. 
Tabel 1. Hasil Pengukuran Parameter Kualitas Air

\begin{tabular}{|c|c|c|c|c|c|c|c|c|}
\hline \multirow[t]{2}{*}{ No } & \multirow[t]{2}{*}{ PARAMETER } & \multirow[t]{2}{*}{ SATUAN } & \multicolumn{4}{|c|}{ KELAS MUTU AIR } & \multirow[t]{2}{*}{ HASIL } & \multirow[t]{2}{*}{ METODE } \\
\hline & & & 1 & II & III & IV & & \\
\hline 1 & $\begin{array}{l}\text { Residu } \\
\text { Tersuspensi (TSS) }\end{array}$ & $\mathrm{mg} / \mathrm{L}$ & 50 & 50 & 400 & 400 & 19 & Spectrofotometri \\
\hline 2 & $\begin{array}{l}\text { Residu Terlarut } \\
\text { (TDS) }\end{array}$ & $\mathrm{mg} / \mathrm{L}$ & 1000 & 1000 & 1000 & 2000 & 33 & TDS Meter \\
\hline 3 & Temperatur & ${ }^{\circ} \mathrm{C}$ & deviasi 3 & $\begin{array}{l}\text { deviasi } \\
3\end{array}$ & $\begin{array}{l}\text { deviasi } \\
3\end{array}$ & $\begin{array}{l}\text { deviasi } \\
5\end{array}$ & 26,8 & Ion selektif \\
\hline 4 & Turbidity & skala NTU & 25 & 25 & 25 & 25 & 30 & Turbiditimeter \\
\hline 5 & Arsen (As) & $\mathrm{mg} / \mathrm{L}$ & 0,05 & 1 & 1 & 1 & 0,00 & Spectrofotometri \\
\hline 6 & Amoniak (NH4) & $\mathrm{mg} / \mathrm{L}$ & 0,5 & $(-)$ & $(-)$ & $(-)$ & 0,37 & Spectrofotometri \\
\hline 7 & Warna & Pt.Co & 50 & 50 & 50 & 50 & 152 & Spectrofotometri \\
\hline 8 & Besi (Fe) & $\mathrm{mg} / \mathrm{L}$ & 0,3 & $(-)$ & $(-)$ & $(-)$ & 0,895 & SM.ed21*2005 \\
\hline 9 & Cadmium (Cd) & $\mathrm{mg} / \mathrm{L}$ & 0,01 & 0,02 & 0,03 & 0,04 & 0,00 & Spectrofotometri \\
\hline 10 & COD & $\mathrm{mg} / \mathrm{L}$ & 10 & 25 & 50 & 100 & 12 & Spectrofotometri \\
\hline 11 & BOD & $\mathrm{mg} / \mathrm{L}$ & 2 & 3 & 6 & 12 & 2,7 & BOD Meter \\
\hline 12 & DO & $\mathrm{mg} / \mathrm{L}$ & 6 & 4 & 3 & 0 & 4,36 & DO Meter \\
\hline 13 & Fluorida (F) & $\mathrm{mg} / \mathrm{L}$ & 0,5 & 1,5 & 1,6 & $(-)$ & 0,013 & Spectrofotometri \\
\hline 14 & Klorida & $\mathrm{mg} / \mathrm{L}$ & 600 & $(-)$ & $(-)$ & $(-)$ & 10 & Spectrofotometri \\
\hline 15 & Klorin Bebas & $\mathrm{mg} / \mathrm{L}$ & 0,03 & 0,04 & 0,05 & $(-)$ & 0,00 & Spectrofotometri \\
\hline 16 & $\begin{array}{l}\text { Kromium Valensi } \\
6\end{array}$ & $\mathrm{mg} / \mathrm{L}$ & 0,05 & 0,05 & 0,05 & 1 & 0,00 & Spectrofotometri \\
\hline 17 & Kalsium (Ca) & $\mathrm{mg} / \mathrm{L}$ & 200 & 2000 & 200 & 200 & 5 & Spectrofotometri \\
\hline 18 & $\begin{array}{l}\text { Kesadahan } \\
\text { (CaCo3) }\end{array}$ & $\mathrm{mg} / \mathrm{L}$ & 500 & 500 & 500 & 500 & 20 & Spectrofotometri \\
\hline 19 & Merkuri (Hg) & $\mathrm{mg} / \mathrm{L}$ & 0,001 & 0,002 & 0,002 & 0,005 & 0.0002 & AAS \\
\hline 20 & Mangan (Mn) & $\mathrm{mg} / \mathrm{L}$ & 0,1 & $(-)$ & $(-)$ & $(-)$ & 0,002 & Spectrofotometri \\
\hline 21 & Nitrat (NO3) & $\mathrm{mg} / \mathrm{L}$ & 10 & 10 & 20 & 20 & 0,162 & Spectrofotometri \\
\hline 22 & Nitrit (NO2) & $\mathrm{mg} / \mathrm{L}$ & 0,06 & 0,06 & 0,06 & $(-)$ & 0,012 & Spectrofotometri \\
\hline 23 & $\mathrm{Ph}$ & $\mathrm{mg} / \mathrm{L}$ & $6,5-9,0$ & $6,0-9,0$ & $6,0-9,0$ & $5,0-9,0$ & 6,03 & Spectrofotometri \\
\hline 24 & Selenium (Se) & $\mathrm{mg} / \mathrm{L}$ & 0,01 & 0,05 & 0,05 & 0,05 & 0,00 & Spectrofotometri \\
\hline 25 & Seng $(Z n)$ & $\mathrm{mg} / \mathrm{L}$ & 0,05 & 0,05 & 0,05 & 2 & 0,03 & Spectrofotometri \\
\hline 26 & Sianida $(\mathrm{CN})$ & $\mathrm{mg} / \mathrm{L}$ & 0,02 & 0,02 & 0,02 & $(-)$ & 0,00 & Spectrofotometri \\
\hline 27 & Sulfat (SO4) & $\mathrm{mg} / \mathrm{L}$ & 400 & $(-)$ & $(-)$ & $(-)$ & 16 & SM.ed21*2005 \\
\hline 28 & Sulfida (H2S) & $\mathrm{mg} / \mathrm{L}$ & 0,002 & 0,002 & 0,002 & $(-)$ & 0,001 & Spectrofotometri \\
\hline 29 & Timbal Pb) & $\mathrm{mg} / \mathrm{L}$ & 0,03 & 0,03 & 0,03 & 1 & 0,001 & AAS \\
\hline 30 & Tembaga (Cu) & $\mathrm{mg} / \mathrm{L}$ & 0,02 & 0,02 & 0,02 & 0,2 & 0,00 & Spectrofotometri \\
\hline 31 & Total Fosphat & $\mathrm{mg} / \mathrm{L}$ & 0,2 & 0,2 & 1 & 5 & 0,085 & Spectrofotometri \\
\hline 32 & Fenol & $\mathrm{mg} / \mathrm{L}$ & 0,001 & 0,001 & 0,001 & $(-)$ & 0,002 & Spectrofotometri \\
\hline
\end{tabular}




\begin{tabular}{|l|l|l|l|l|l|l|l|l|}
\hline 33 & $\begin{array}{l}\text { Minyak dan } \\
\text { Lemaak }\end{array}$ & $\mathrm{mg} / \mathrm{L}$ & 1 & 1 & 1 & $(-)$ & 0,23 & Gravimetri \\
\hline & Deterjen (MBAS) & $\mathrm{mg} / \mathrm{L}$ & 0,2 & 0,2 & 0,2 & $(-)$ & 0,035 & Spectrofotometri \\
\hline
\end{tabular}

Sumber : Hasil Analisis Tahun 2017

Dari tabel menunjukan ada beberapa parameter yang masih diatas baku mutu yaitu parameter kekeruhan, amoniak, warna dan besi, hal ini di pengaruhi waktu pengambilan sampel pada kondisi debit banjir akibat musim hujan sehingga mempengaruhi sampel. Selain itu juga jika tingkat parameter seperti kekeruhan jika melebihi ambang batas akan mempengaruhi proses kehidupan organisme yang ada diperairan, apabila kadar kekeruhan dalam air tinggi maka kandungan oksigen akan menurun, hal ini disebabkan intensitas cahaya matahari yang masuk ke dalam perairan sangat terbatas sehingga makhluk hidup seperti phytonplankton tidak dapat melakukan fotosintesis untuk menghasilkan oksigen. Warna juga dapat menghambat penetrasi cahaya ke dalam air. Warna pada air disebabkan oleh adanya partikel hasil pembusukan bahan organik, ion-ion metal alam (besi dan mangan), plankton, humus, buangan industri, dan tanaman air. Adanya oksida besi menyebabkan air berwarna kemerahan, sedangkan oksida mangan menyebabkan air berwarna kecoklatan atau kehitaman. Kadar besi sebanyak $0,3 \mathrm{mg} / \mathrm{l}$ dan kadar mangan sebanyak $0,05 \mathrm{mg} / \mathrm{l}$ sudah cukup dapat menimbulkan warna pada perairan.

\section{b. Klasifikasi Lahan dan Hutan Oleh Masyarakat Adat}

Berdasarkan pendekatan tentang tata guna lahan oleh masyarakat, lokasi dan jenis sumber daya alam yang penting untuk masyarakat, kearifan lokal dan peraturan adat untuk mengatur pemanfaatan SDA (Sumber Daya Alam) membuktikan keterikatan masyarakat dengan lingkungan dan sumber daya alam di wilayah adatnya yang menciptakan pola pemanfaatan lahan yang khas dan sangat berkaitan dengan spesifikasi lingkungan. Ancaman terhadap perusakan hutan secara besar-besaran yang berasal dari luar wilayah desa, misalnya perusahaan sawit dengan menggunakan peralatan modern dapat merusakkan ribuan hektar sumber daya hutan yang bermanfaat bagi masyarakat dan mengganggu sungai dalam waktu singkat. Konversi hutan untuk berbagai kepentingan dengan membuka areal hutan yang luas juga dapat terjadi dalam waktu yang tidak terlalu lama. Demikian pula dengan binatang buruan yang ditangkap menjadi semakin banyak jumlahnya sehingga pada akhirnya menjadi pesaing yang dapat mengurangi hasil tangkapan penduduk setempat, Akhirnya jika tidak ada pembatasan, dari masyarakat luar yang masuk dalam jumlah besar dapat menimbulkan konflik dengan masyarakat.Dalam aturan adat yang telah ditetapkan berdasarkan Keputusan Musyawarah Adat Besar, telah diatur yang intinya membatasi pengusaha untuk merusak dan memungut hasil hutan seperti: gaharu, rotan, kayu manis, dan hasil hutan lainnya. Pengusaha-pengusaha dari luar daerah tidak diperkenankan memungut hasil hutan secara langsung, tetapi boleh membeli dari masyarakat dengan ijin dari pemerintah desa Pisak. Pengusaha hasil hutan asal putra daerah yang sudah pindah ke tempat lain, diperkenankan dalam waktu terbatas untuk satu sampai tiga orang dan bergabung dengan masyarakat setempat. Pengusaha hasil hutan yang masuk tanpa ijin, didenda Rp. 1.500 .000 per orang, uangnya masuk kas adat.. Dengan adanya pengaturan hutan berdasarkan hukum adat secara lokal maka konflik dapat dicegah. 


\section{c. Analisis Kearifan Lokal Masyarakat Berdasakan Data Kuesioner}

Masyarakat Desa Pisak sendiri memiliki kepercayaan yang masih berhubungan dengan keyakinan terhadap kepercayaan leluhur. Pada proses wawancara kepada masyarakat Mereka meyakini kepercayaan leluhur dapat mengendalikan kondisi hutan agar tetap terjaga kelestariannya, selain itu juga para leluhur masyarakat Desa Pisak menurunkan aturan-aturan yang secara turun-temurun masih diterapkan oleh semua masyarakat dan orang-orang yang berkunjung di Desa Pisak. kearifan lokal yang ada dalam masyarakat dapat berupa: nilai, kepercayaan sanksi dan aturan-aturan khusus. Bentuk dari kearifan lokal akan menghasilkan suatu bentuk implementasi atau suatu proses yang berlansung dalam menjaga sumber daya air. Dari proses kearifan lokal ini akan dipengaruhi oleh faktor eksternal dan internal dalam pelaksanaannya, faktor ini sangat mempengaruhi perubahan dari proses kearifan lokal.

Aturan-aturan atau larangan yang diterapkan masyarakat Desa Pisak yaitu:

1. Dilarang menebang pohon dilokasi hutan dan tembawang milik masyarakat Desa Pisak dusun Dawar.

2. Tidak boleh diperjual belikan pohon-pohon khususnya pohon durian di lokasi tembawang milik masyarakat adat oleh kelompok tertentu demi meraih keuntungan.

3. Dilarang memasuki areal hutan adat desa Pisak tanpa izin kepala adat.

4. Dilarang merusak area hutan adat.

5. Dilarang mandi sembarangan tanpa izin masyarakat Desa.

Adapun sangsi yang diberlakukan jika melanggar aturan-aturan yang diberlakukan yaitu:

1. Mengeluarkan 1 buah manduh (labu)

2. Mengeluarkan babi 1 ekor $(50 \mathrm{~kg})$.

3. Ayam 3 ekor $(2 \mathrm{~kg})$.

4. Anjing 1 ekor (10 kg).

5. Beras $50 \mathrm{~kg}$

6. Bia bius dikeluarkan oleh pelanggar.

7. Bayar ritual Rp. 1.000.000,-

8. Denda Rp. 5.000.000,-

Masyarakat telah menyadari ketergantungannya dengan hutan, maka Desa Pisak memiliki aturan pemanfaatan dan pengelolaan hutan, Aturan ini pada dasarnya adalah untuk mencegah konflik mengenai berbagai kepentingan dalam masyarakat, salah satunya adalah dengan menerapkan hukum adat untuk mengatur pengelolaan hutan yang mencerminkan ketergantungan masyarakat pada hutan, misalnya adalah 'tana ulen'. Hukum adat yang berlaku dari dulu merupakan hukum adat yang tidak tertulis. Sedangkan hukum negara merupakan hukum tertulis. Kadang-kadang hukum adat dan hukum negara saling mengisi. Hukum adat dan hukum negara saling mengisi, yakni apabila hukum adat belum mengatur, maka hukum negara yang mengaturnya. Sebaliknya apabila dalam hukum negara tidak ada, maka hukum adat yang mengaturnya. Apabila kedua-duanya ada pengaturannya maka yang diutamakan lebih dulu adalah pengaturan hukum adat, karena hukum adatlah yang lebih sesuai berdasarkan kondisi, situasi, dan pengalaman sejarahnya. Peran pemimpin sangat berpengaruh dalam kepercayaan masyarakat, hal ini mencakup lingkungan internal 
yang berkaitan dengan upaya menggerakkan dan memastikan seluruh masyarakat dapat berperan dalam kinerja, khususnya dalam pelestarian lingkungan. Pada wawancara kepada masyarakat (Bapak Kadus) menuturkan bahwa pemimpin yang cerdas bukanlah jaminan untuk mengepalai desa mereka, seorang pemimpin selain memiliki pengetahun dan keterampilan untuk memimpin juga dituntut berperilaku yang dapat menjadi panutan atau contoh bagi masyarakat. Sebagai pemimpin yang menjadi panutan atau contoh masyarakat Desa Pisak adalah kepala adat (Bapak Kundil) beliau merupakan kepala adat yang telah menjabat kulang lebih 15 tahun, beliau dipilih menjadi kepala adat bukan berdasarkan tingkat pendidikan maupun kecerdasan, melainkan dipilih berdasarkan pengalaman hidup, usia, dan latar belakang kepribadiannya sangat kuat mempengaruhi masyarakat akan tindakan, baik dalam arti positif dan negatif.

\section{d. Implementasi Kearifan Lokal Dalam Menjaga Sumber Daya Air}

Sungai Tanggi sendiri melewati kawasan hutan yang mencakup Desa Pisak, sungai Tanggi sendiri memiliki berbagai macam habitat berupa ikan, udang dan hewan-hewan lainnya, terdapat larangan-larangan yang diterapkan masyarakat desa untuk memanfaatkan hasil sungai diantarannya dilarang menggunakan racun atau Tuba, bom ikan dan sejenisnya yang dapat merusak ekosistem sungai dan kualitas air sungai Tanggi, Masyarakat Desa biasanya menggunakan alat yang ramah lingkungan seperti pancing, jala, bubu, dan panah. Alat-alat tersebut bersifat ramah lingkungan tidak merusak ekosistem sungai, sehingga ekosistem dapat terjaga kelestariannya. Masyarakat telah menyadari ketergantungannya dengan hutan, maka Desa Pisak memiliki aturan pemanfaatan dan pengelolaan hutan, Aturan ini pada dasarnya adalah untuk mencegah konflik mengenai berbagai kepentingan dalam masyarakat, salah satunya adalah dengan menerapkan hukum adat untuk mengatur pengelolaan hutan yang mencerminkan ketergantungan masyarakat pada hutan, misalnya adalah 'tana ulen'. Hukum adat yang berlaku dari dulu merupakan hukum adat yang tidak tertulis. Sedangkan hukum negara merupakan hukum tertulis. Kadang-kadang hukum adat dan hukum negara saling mengisi. Hukum adat dan hukum negara saling mengisi, yakni apabila hukum adat belum mengatur, maka hukum negara yang mengaturnya. Sebaliknya apabila dalam hukum negara tidak ada, maka hukum adat yang mengaturnya. Apabila kedua-duanya ada pengaturannya maka yang diutamakan lebih dulu adalah pengaturan hukum adat, karena hukum adatlah yang lebih sesuai berdasarkan kondisi, situasi, dan pengalaman sejarahnya. Selain itu terdapat larangan memasuki Hutan secara sembarangan oleh masyarakat Desa Pisak, larangan tersebut wajib di taati oleh masyarakat Desa dan orang-orang yang memasuki Desa Pisak, jika terdapat pelanggaran akan dikenakan sangsi adat sama seperti sangsi menebang pohon.

\section{e. Analisis Data Kuesioner}

Pada penelitian ini menggunakan kuesioner berjumlah 13 pertannyaan dengan 6 pertannyaan bersifat biodata pribadi responden, Dari pertannyaan tersebut masyarakat Desa Pisak sudah mengetahui dan menerapkan aturan-aturan dari pemerintah daerah maupun pemerindah pusat, aturan-aturan tersebut disebar diseluruh masyarakat desa dan dilakukan penyuluhan pada saat dilakukannya upacara adat sehingga semua masyarakat Desa dapat memahami dan penerapkan dari aturan-aturan tersebut. 


\section{f. Analisis Penggunaan Lahan}

Desa pisak sendiri memiliki berbagai jenis pertanian dan perkebunan, penggunaan lahan Desa Pisak terdapat penggunaan untuk perkebunan, pertanian, dan kawasan hutan. Untuk kawasan hutan sudah termasuk kawasan DAS (Daerah Aliran Sungai).

Tabel 2. Jumlah Penggunaan Lahan Desa Pisak Tahun 2017

\begin{tabular}{|c|c|c|c|c|c|c|c|c|}
\hline Tahun & Desa & DAS_HA & DAS_km & Pemukiman & $\begin{array}{l}\text { Cagar } \\
\text { Alam }\end{array}$ & $\begin{array}{c}\text { Taman } \\
\text { Nasional }\end{array}$ & $\begin{array}{c}\text { APL (Area } \\
\text { Penggunaan } \\
\text { Lainnya) }\end{array}$ & $\begin{array}{l}\text { Hutan } \\
\text { Rakyat }\end{array}$ \\
\hline Tahun & & 14,060 & & & 111,10 & 39,440 & & \\
\hline 2015 & Pisak & $\mathrm{HA}$ & $12,5 \mathrm{~km}$ & $27,90 \mathrm{HA}$ & HA & $\mathrm{HA}$ & $140 \mathrm{HA}$ & $50,37 \mathrm{HA}$ \\
\hline Tahun & & 14,069 & & & 111,13 & 33,893 & & \\
\hline 2016 & Pisak & $\mathrm{HA}$ & $12,5 \mathrm{~km}$ & $38,03 \mathrm{HA}$ & $\mathrm{HA}$ & $\mathrm{HA}$ & $145,31 \mathrm{HA}$ & $50,37 \mathrm{HA}$ \\
\hline
\end{tabular}

Sumber : Hasil Analisis 2017

Untuk DAS sungai Tanggi memiliki panjang $12,5 \mathrm{~km}$, dengan debit minimum sebesar $26,88 \mathrm{~m}^{3} /$ detik dan debit maksimum sebesar $35,32 \mathrm{~m}^{3} /$ detik. Sedangkan untuk luasnya sebesar 14,069 hektar. Luasan penggunaan lahan Desa Pisak pada tahun 2016 sebesar 405,301 hektar, sedangkan untuk tahun 2015 sebesar 395,379 hektar jika dihitung perbedaan tahun 2015 dan 2016 berkurang sebesar 9,922 hektar, hal tesebut dikarenakan terjadinya kebakaran hutan pada tahun 2015 yang merambah areal hutan adat Desa Pisak, lahan yang terbakar diambil alih oleh pemerintah untuk dilakukan proses pemulihan lahan.

\section{PENUTUP}

a. Kesimpulan

1. Peran Masyarakat Desa Pisak dalam menjaga kelestarian Sumber Daya Air di lakukan melalui:

- Menerapkan aturan-aturan atau larangan seperti dilarang menebang pohon dilokasi hutan dan DAS (Daerah Aliran Sungai).

- Melakukan ritual Adat yang bertujuan untuk menjaga alam khususnya hutan dan sungai agar tetap terjaga kelestariannya.

2. Kearifan lokal masyarakat Desa Pisak dalam menjaga kelestarian sumber daya alam di nilai sangat baik hal ini dilihat dari peta perubahan tata guna lahan yang hanya mengalami perubahan sebesar 9,922 hektar selama kurun waktu 1 tahun.

b. Saran

1. Perlu penelitian lanjutan mengenai kearifan lokal dan tradisi masyarakat Desa Pisak.

2. Dengan diketahuinya kearifan lokal masyarakat Desa Pisak, maka diharapkan akan menjadi tolak ukur dalam menentukan pembangunan yang ideal yang dapat dijalankan di lokasi penelitian.

\section{UCAPAN TERIMAKASIH}

Dengan selesainya penelitian ini saya mengucapkan terimakasih yang sebesarbesarnya kepada Tuhan Yang Maha Esa, kedua orang tua saya, serta kepada dosendosen pembimbing yang bersedia membimbing saya sampai berakhirnya penelitian 
ini, serta kawan-kawan Teknik angkatan 2012 dan semua orang yang telah berperan dalam membantu penelitian ini. Besar harapan saya penelitian ini dapat bermanfaat bagi semua dan dapat di pergunakan sebagai mestinya.

\section{DAFTAR PUSTAKA}

Arafah, N, (2002). Pengetahuan Lokal Suku Moronene Dalam Sistem Pertanian Di Sulawesi Tenggara. Program Pascasarjana Institut Pertanian Bogor.

Arikunto, S, (2002). Prosedur Penelitian, Suatu Pendekatan Praktek. Jakarta: PT Rineka Cipta.

Asdak, Chay, (2010). Hidrologi Dan Pengelolaan Daerah Aliran Sungai, Gadjah Mada University. Yogyakarta.

Erwin, (2014). Pola Pemanfaatan Sumber Daya Air Sungai Mesanga Oleh Penduduk Desa Kaluku. Untad.

Fauzi, A, (2004). Ekonomi Sumber Daya Alam Dan Lingkungan. PT. Gramedia. Pustaka Utama. Jakarta.

Ishak, (2008). Pengelolaan Berbasis Teknologi Informasi. Pustaka Indonesia.

Kodoatie, R. J. dan Sjarief, R, (2005). Pengelolaan Sumberdaya Air Terpadu. Andi. Yogyakarta.

Komalasari, (2011). Pembelajaran Kontekstual Konsep Dan Aplikasi. Bandung.

Muh. Ali Akbar Latif, (2012). Study Kualitas Dan Kuantitas Air Sungai Tallo Sebagai Sumber Air Baku. Universitas Hasanudin.

Notoatmodjo, Soekidjo, (2003). Pendidikan Dan Perilaku Kesehatan. Rineka Cipta. Jakarta.

Peraturan Menteri Kehutanan Nomor: P. 39/Menhut-II/2009. Tentang Pengelolaan dan Perlindungan Lingkungan Hidup.

Putnam, R.D. (1995). Turning In, Turning Out: The Strange Disappearance of Sosial Capital in America. Political Science and Politics 28.

Pretty, J., Ward, H. 2001. Sosial Capital and The Environment. World Development Vol. 29, No. 2.

Ridwan,N, (2007). Landasan Keilmuan Kearifan Lokal. http://ibda.files.wordpress.com/2008/04/2-landasan-keilmuan- kearifanlokal.pdf.

Saleh,T.dan Rasul ,R, (2008). Pengenalan Pengelolaan Sumberdaya Air. http://repository.ui.ac.id/contents/koleksi/11/db20326d7baed0dca1bebc8428f6 f2ee4fbd2e0b.pdf. diakses 20 November 2009, pukul 12:48.

Sartini, (2004). Menggali Kearifan Lokal Nusantara Sebuah Kajian Filsafat. Jurnal Filsafat: Agustus 2004, Jilid 37, Nomor 2. 